\section{EMBRYARIDDLE Aeronautical University}

SCHOLARLY COMMONS
International Journal of Aviation, Aeronautics, and Aerospace

\title{
Global Aviation System: Towards Sustainable Development
}

\author{
Marina P. Bonser Dr. \\ Saint Petersburg State University of Civil Aviation, dr.m.bonser@comcast.net
}

Follow this and additional works at: https://commons.erau.edu/ijaaa

Part of the Aviation and Space Education Commons, Aviation Safety and Security Commons, Bilingual, Multilingual, and Multicultural Education Commons, Business Administration, Management, and Operations Commons, Business Analytics Commons, Computational Engineering Commons, Curriculum and Social Inquiry Commons, Engineering Education Commons, International and Comparative Education Commons, International Business Commons, Management and Operations Commons, Management Information Systems Commons, Multi-Vehicle Systems and Air Traffic Control Commons, Navigation, Guidance, Control and Dynamics Commons, Operations Research, Systems Engineering and Industrial Engineering Commons, Organizational Behavior and Theory Commons, Organization Development Commons, Public Affairs, Public Policy and Public Administration Commons, Strategic Management Policy Commons, Systems Engineering and Multidisciplinary Design Optimization Commons, Technology and Innovation Commons, and the Training and Development Commons

\section{Scholarly Commons Citation}

Bonser, M. P. (2019). Global Aviation System: Towards Sustainable Development. International Journal of Aviation, Aeronautics, and Aerospace, 6(3). https://doi.org/10.15394/ijaaa.2019.1356

This Concept Paper is brought to you for free and open access by the Journals at Scholarly Commons. It has been accepted for inclusion in International Journal of Aviation, Aeronautics, and Aerospace by an authorized administrator of Scholarly Commons. For more information, please contact commons@erau.edu. 


\section{Global Aviation System: Towards Sustainable Development}

\section{Cover Page Footnote}

Highlights: - The aviation industry has integrated into a global system. Integration processes need to be lead to the sustainable development of the system. - Global systems thinking is essential for strategic management of a global system. - Globally affluent research authorities should control investment to the industry. - Global language proficiency needs to be enriched with cross-cultural competence. 


\section{Introduction}

Aviation is an industry which is international in nature. The attempts of building flying devices inspired by the human dream of flying are in the history of many countries around the world. Industrial revolution lifted these initiatives up into the new level. Nowadays the majority of the countries in the world has air transportation, and it is getting more available and more popular around the world. Aviation made reachable every corner on the planet easier, and it has great perspectives for continuous advance in technology, management, communication, psychology, and education. Aviation in most of the countries, as well as international aviation structures, such as airport security and air traffic management, are developing rapidly and getting more complex. It increases the complexity of international communication. The most internationally popular language in the world is English, and it is the language of aviation. Crystal comprehensively explained of how and why English became a Global Language (Crystal, 2003). Worldwide education is challenged by the demand to satisfy global communication needs.

\section{Integration Processes in Aviation: Building a Global System}

Aviation is one of the tools for the world's integration process which started at the end of the $20^{\text {th }}$ century. "Integration can be defined as a process of harmoniously blending of different components into a system, where those components become interrelated with all other components of the system, they complement each other, and assembled system is able to successfully function as a whole unit" (Bonser, 2016, para.3). Integration appears in globalization and internationalization of cultures, technologies, businesses, and education, and aviation plays a significant role in the process of connecting them. Modern world languages, religions, and philosophical views have also started to change toward integration to keep up with changes in life. The result of the proper integration is sustainable development, the development of a system which doesn't destroy its surroundings and sources of its life (Bonser, 2016). The formation of the International Civil Aviation Organization (ICAO) in 1944 at Chicago Convention indicated that aviation had been grown into a global system which needs international standards and regulations for the management of international interactions in all areas and levels of aviation for the purpose of safety and also for effectiveness in functioning.

Unification is the first essential stage of building a global system in order to align all the parts of it together. When the global system is formed, it continues to grow. Aligning all parts with global standards was the condition for the effective functioning of the whole system as well as for each part of it. At some point, when the system gains stability, it is ready to engage the new potential for increasing effectiveness in functioning which is welcoming and maintaining diversity. Exploring and customizing local needs brings a wide array of local varieties of combinations of them to add to their global common components. It is like constructing different buildings from the same several 
kinds of building blocks with different additional details for each type of buildings and with unique details for each building. Differentiation of the integrated system is the second stage of the development. Diversity gives a wider potential to a system for the better flexibility and adjustment for survival in changing conditions and for the further development. Nowadays the global aviation system has a variety of reasonable local differences at the different levels in airport layouts and airlines management which all comply with ICAO standards and regulations.

Global communication, global technological advance, and global strategic management proficiencies are the conditions for the successful functioning of the global aviation system. They naturally increased via the experience of operating within the global system, and also can be escalated and advanced with the help of education and training courses.

Processes of integration continue to form modern aviation system in following global aspects:

1. Growing need for global language proficiency for communication within the global system increases quantity and quality of the language education and training courses. Expanding and deepening this proficiency are becoming more essential for everyone involved in international aspects in aviation.

2. Growing technological advance and integration increase quantity and quality of integrated multifunctional systems in avionics based on the new informational technologies for aircraft, air traffic control, and airport equipment. Expanding and deepening this proficiency are becoming more essential for everyone involved in technological aspects in aviation.

3. Globalization of worldviews and thinking toolkits within the management on the levels where international interactions are involved. Expanding and deepening this proficiency are becoming more essential for everyone involved in strategic management aspects in aviation.

\section{Global Communication Proficiency}

English language proficiency became an essential requirement for safety in all aspects of international aviation, and there is a growing need for it within any national aviation which has to keep up with the rest of the aviation world. It is becoming more and more effective to align domestic standards and rules with international ones when dealing with technical documentation, airport security, and flight safety. New technologies and international communication are getting more essential for growing not only international but also domestic aviation business for handling more flights in more effective ways, reducing delays, fuel consumption, emission, and noise pollution.

Proper cross-cultural communication is also a significant part of the world's integration. There is a clear need for cross-cultural communication literacy in many aspects of aviation. Knowing the language without proper 
evaluation of potential cultural differences might not be enough for handling international communications effectively and cause serious problems, especially in emergency cases. That is why cross-cultural awareness and communication literacy should be included in programs for the training of different areas of expertise as a part of international communication proficiency along with traditional language proficiency.

There are many examples of accidents caused by cross-cultural issues. The broadly known collision of Tupolev Tu-154 passenger jet and Boeing 757 DHL cargo jet on July 1, 2002, in mid-air over German city Uberlingen is one example. The official investigation by the German Federal Bureau of Aircraft Accident Investigation (BFU) identified two main causes of the collision: a number of shortcomings on the part of the Swiss Air Traffic Control (ATC) service in charge of the sector involved, and ambiguities in the procedures regarding the use of TCAS, the onboard Traffic Collision Avoidance System (German Federal Bureau of Aircraft Investigations, 2004). Both parties were aware of the problem but had different approaches to solving a contradiction between air traffic controller instructions and onboard TCAS data. They had different cultural customs in prioritizing one over another. Russian pilots prioritized ATC instructions over TCAS while the British pilot and Canadian co-pilot of the DHL aircraft had the opposite priority. As a result, both airplanes tried to avoid the collision by choosing to descend, rather than climbing, and collided into each other.

More detailed description of a cross-cultural aspect of the accident can be found in the news article written for "The Scotsman" magazine by Gallagher in 2004. Accidents caused by a cross-cultural type of misunderstanding indicated the need for international rules within the world's aviation which everyone involved would know and follow. ICAO officially met this need in November 2003 by amending its regulations with recommendations to always prioritize TCAS advisories over ATC instructions (Flight Safety Foundation, 2004).

The general aspects of cross-cultural communication in the context of aviation are:

1. Contents of international communication between pilots and traffic controllers;

2. Information management within the systems of air traffic control between all parties;

3. Aircraft maintenance documentation, especially emergency maintenance in foreign countries; and

4. Airport services, all personnel directly and indirectly connected to aviation.

The International Civil Aviation English Association (ICAEA) developed a new concept of managing communications as a factor in aviation safety. In 2018, ICAEA held an international conference for exploration of global communication needs beyond ICAO Language Proficiency Requirements (LPRs) which included incorporating communication strategies 
into the best practices for training and testing, the effect of language and culture on communication as a human factor, and considerations for the future policy developments in language and communication. "ICAO LPRs address speaking and listening requirements for pilot and air traffic controller communications. Implementing the LPRs into effective aviation English training and testing programs is an ongoing challenge for civil aviation authorities, airlines, air navigation service providers and training organizations. The ICAO LPRs do not specifically address the wide range of English language requirements that impact aviation safety across a range of communication scenarios which affect flight safety, including:

- Issues that impact the effectiveness of inter-cultural communication including language proficiency, cultural awareness and native-speaker accommodation skills, on the flight-deck, between ATC and aircraft and on the ground;

- English proficiency required for effective flight crew communications for threat and error management and crew resource management;

- The language needs of the wider aviation professions, including maintenance staff and cabin crew;

- English reading and reporting proficiency required for effective and safe maintenance of aircraft, including comprehension of manuals, completing reports, and communications with flight crew and airline personnel." (ICAEA International conference, 2018, Conference theme description)

Based on these stated needs, development of a global system of aviation resulted in the next stage of the global communication development; enriching English education with cross-cultural awareness. It gives a deeper understanding of an information communicated than just gaining vocabulary and skills of sentences' construction, and makes communication more effective. This is the second stage of global system development in the communication context (maintaining diversity) after the stage of global language education (maintaining unification).

The importance of cross-cultural awareness is broadly recognized by psychologists. Hofstede analysed the broad spectrum of the differences in thinking and social action between representatives of the most modern nations. His concept of mental programs developed in early childhood claimed to be the new benchmark for scholars and professionals for years to come (Hofstede, 2001).

The practice of Crew Resource Management (CRM) training, which prepares a crew for more effective teamwork in emergency situations, showed that effective communication escalates the effectiveness of work (Page \& Trembly, 2015). It makes cross-cultural awareness an essential component for communication in the training for multicultural teams. "Airlines must adopt culture-specific training if they are to capitalize on the strengths of crewmembers of all nationalities (Bjellos, 2012, Crossline sections). 
Cross-cultural literacy includes the concept of tolerance which would be very helpful in international aviation practice, directly in communications, and indirectly within governmental, business, technical, and legal documentation. Deep understanding of tolerance is definitely an advantage over just following the rules in aviation practice. The USA is a country broadly welcoming multiple cultures and religions, a melting pot, and they have good working policy and practice of tolerance to the differences between people. This has helped influence other countries that are becoming multicultural.

Cross-cultural awareness brings understanding that the different conditions of life shape different worldviews, nationally, locally, and individually. It develops tolerance to diversity and respect to the different concepts and opinions. The "Worldview Relativity Principle" is similar to the well-known Einstein's Relativity Principle of reference frames in physics (Pushnaya, 2018). It expands one's horizons of the world vision, increases strategic thinking abilities, and helps to develop a global consciousness. This principle is the other side of the Whorf's Linguistic Relativity Principle (Whorf, 1956), which states that the language reflects the culture which developed it. That's why knowing foreign languages brings more opportunities for understanding other cultures and their common worldviews.

Integration is not only bridging cultural differences around the world but it is developing the new international culture mostly on the basis of the new technology which spreads out the information around the world very fast. Informational Technology (IT) gave birth to the international words like "computer," "internet," and many others which sound the same in all world languages. IT makes a major contribution to forming new international language, mostly on the basis of global language English with inclusion broadly known words from other languages around the world like "sushi" and "pizza." According to the Whorf's Linguistic Relativity Principle, it indicates the development of the global culture which is a new social formation in human history.

To maintain a proficiency in any field in modern world, professionals need to be involved in worldwide social networks in their fields to stay on top of changes in their professional worlds and be aware of new problems and innovations worldwide. They need global communication proficiency besides the expertise in their fields.

\section{Global Vision and Global Systems Thinking for the Management of a Global System}

The advantages of international communication proficiency go far beyond a set of certain communication needs in specific aviation aspects. The ability to see the world from different perspectives, different paradigms significantly helps in the development of strategic systems thinking which increase the quality of performance of solving complex problems and develop 
proper strategies at any specific job in a complex stressful environment which deals with high safety and security needs.

The more global a system is, the more essential it becomes to the effectively management it. It makes the need for global worldview and global systems thinking more essential for anyone involved in higher levels of management of a global system. Also, as the integration processes continue, the more local systems and aspects of life get involved in the global system to a higher degree. Global worldview and strategic thinking abilities are gradually becoming more essential for professionals in numerous fields. To keep up with changes at work and in life, and for the better forecasts and management, people need to understand where those changes are coming from, how they are related to each other and to the other different aspects, how they are structured, and what patterns they are evolving with.

Global Worldview is a holistic worldview, with the unity and interconnectedness of all subjects, processes, and phenomena in the world... First, a person accumulates global competence, and then this quantity accumulation turns into a new quality: systematization of global knowledge finally leads to the global worldview. Gradually, operating with a global worldview, placing all new information in it, or rebuilding it to place a new information, just like assembling a puzzle, students train their thinking structures until they are trained enough to turn into a new quality of thinking. At this stage thinking becomes global, so the mind is able to operate successfully with global systems and processes...Global Thinking is a system of united thinking toolkit which is integrated from all known kinds and methods of thinking (logical, lateral, creative, critical, etc.) ...Global Thinking is a kind of creative thinking which becomes Systems Thinking via operating with global categories. (Bonser, 2011, para. 2, 4, 5, 8).

Global (Universal and/or Holistic) Thinking is a fundamental tenant of the Global Education concept developed by Hanvey (1987). Global Thinking is one of the ways of finding solutions to existing and future global problems. Global Thinking was understood as an ability to think using the categories of whole planet, and to perceive the world as a system of systems and a system of multilevel interdependencies. This concept was enriched with a new content by Pushnaya, and became a functional knowledge anyone can use to develop efficient strategies and solutions (Pushnaya, 2004). Global worldview and global thinking develop naturally during regular interactions with a global system. However, courses for creativity development, systems thinking development, global thinking development speed up and significantly enhance this process.

Systems thinking approach is getting popular for developing strategies and solutions for different systems in the world, especially for local business development. It focuses mainly on the exploration of connections between parts of a system, and/or connections between a system with other systems and the dynamics of their development. Arnold and Wade put together a full 
review of systems thinking definitions and functions (Arnold \& Wade, 2015). The system of the whole world differs from any other system within this world. Global Thinking focuses on the impact of patterns of systems and their interrelations on the whole planet which becomes important in managing a global system. If it comes to the significance of aligning local activities with any kind of global processes or standards, a global component in thinking becomes essential. A person's structures of thinking, "thinking habits spectrum" in one's mind require greater potential for developing strategies and solving problems on a planetary scale than just systems approach. So, the systems thinking needs a global adjustment to deal more successfully with the entire world and can be called Global Systems Thinking (Bonser, 2012).

When it comes to implementation of global consequences on any local levels, the ability to understand them should be enriched with the ability to understand ways of effective local adjustments of them taking into account local scale consistencies. Robertson, who introduced the term "globalization," then popularized the term "glocalization" ("glocal") combined from worlds "globalization" and "localization" ("global" and "local") meaning simultaneous work of universalizing and particularizing tendencies (Robertson, 1995). Globalization can be considered as a leading tendency at the first stage of forming a global system, and glocalization as the leading tendency at the second stage. Originally term "local" meant just geographical location but it might be of a broader use of any particular aspects of a global system.

\section{Integrated Digital Systems for Aircraft, Air Traffic Control, and Airport Equipment}

Aviation equipment is advancing via new technologies and getting more integrated to meet growing needs for the efficiency and management of all ground and airborne operations. Touch screen technology for flight deck instruments, remote ATC towers for several airports, ADS-B (Automatic Dependent Surveillance-Broadcast), SWIM (System Wide Information Management), and SANDRA (Seamless Aeronautical Networking through of Data links, Radios, Antennas) are the examples of integrated systems. Interoperability of the air systems and ground systems with synchronization of equipage and industry investments is the main challenge in avionics development. Watkins and Walter analyzed transitioning from federated avionics architecture to integrated modular avionics (IMA) architecture. "IMA architectures employ a high-integrity, partitioned environment that hosts multiple avionics functions of different criticalities on a shared computing platform. This provides for weight and power savings since computing resources can be used more efficiently... The approach to resource management (computing, communication, and input/output interactions) is identified as the fundamental architectural difference between federated and IMA systems" (Watkins \& Walter, 2007, Abstract). A term "system architecture" rather than just "systems structure" became popular in 
descriptions of avionics technologies. This term shows a higher level of organization, "a toolkit," which allows for options of different structures just like building blocks can be put together into different kinds of buildings. The complexity of a system's architecture complied with the principle of simplification for its building and functioning reflects a degree of integration of a system. It is unifying principle of continuous technological advance towards sustainable development.

\section{The Management of Integration Processes in Avionics by Globally Affluent Research Authorities}

There are next-generation air transportation research and innovation implementation authorities in major aviation and technologically advanced countries, such as NextGen (The Next Generation Air Transportation System) of FAA (Federal Aviation Administration) in the United States, SESAR (Single European Sky ATM (Air Traffic Management) Research) of Eurocontrol in the European Union, and CARATS (Collaborative Actions for Renovation of Air Traffic Systems) in Japan. Complying with ICAO rules and regulations, these systems are developing innovations with the support of private and public partners and other stakeholders.

The innovations and investments flow into next-generation air transportation development needed to be regulated. In 2012, USA Congress requested National Research Council to examine NextGen activities to make sure that all their efforts primarily service the real aviation needs for innovations in the long run without compromising it by making money purposes of businesses within the aviation industry. The general recommendation after examination completion was: "Should FAA continue to act as the systems integrator of NextGen programs, FAA should maintain architectural leadership and not delegate architecture definition and control to contractors" (US National Research Council, 2015, p. 2).

Any socioeconomic system naturally spontaneously follows the easiest available financial flows. It is critical for the survival of many private businesses in ordinary socioeconomic life. However, following the money flow without taking into account possible negative consequences can eventually lead to unwanted results for the business, for its network, and for the surrounding environment. For the successful functioning of the system in the long run, which is sustainable development, there is a need for the management of processes within the system which layout directions of the integration of the system in a sustainable way. Global vision and global systems thinking development is the way which would provide for the development of strategies for sustainable development of global systems. National Research Council's recommendations for FAA form a multilevel sustainable strategy for system integration within the innovations context which is a top leading contribution to sustainable development of the global aviation system. "...NextGen needs an explicit system architecture - in addition to its existing enterprise architecture - to guide its development, 
manage risk, and cope with change. To create this architecture, FAA should build an architecture community and also strengthen its workforce in several technical fields" (US National Research Council, 2015, p. 1).

Nurturing workforce talent in the areas of systems engineering, architecture, systems integration, digital communications, cybersecurity, and raising capable architecture community which will "expand the breadth and depth of expertise that is steering architectural changes" (US National Research Council, 2015, p. 2)., and managing deliverables and investments (for procedure and airspace design, infrastructure deployment, training, and so on) are the components of the next level strategy which is built as an implementation of the general strategy. "On this basis, the industry could responsibly invest as required, given a reasonable expected return." (US National Research Council, 2015, p. 3). The recommendations start with aligning all stakeholders' expectations and establishing a leadership for providing their orientation towards sustainable development. This alignment indicates the unification stage of the development of global aviation system in the technological-economical context of innovations development and implementation. Eventually, FAA supposed to be able successfully manage all varieties of specific technological needs and investments in them.

\section{Conclusion}

Overall, spontaneous integration processes within this system and beyond get shaped towards sustainable development of the system via strategic management:

1. Global language proficiency gets enriched with cross-cultural proficiency which includes multicultural Crew Resource Management (CRM) skills for emergency teamwork for multicultural crews. Enriched global language education and training courses enhance safety and effectiveness in every aspect of aviation.

2. The advancement and integration of technology and technological expertise are guided by globally affluent research authorities who explore and evaluate the potential of this development and manage it in a sustainable way.

3. Natural globalization of worldviews and thinking toolkits are escalated and advanced with global education and global system thinking courses within the management on the levels where international interactions are involved.

Education and training courses for global communication proficiency, for advanced professional expertise, and for global systems thinking development is the force which shapes the system's integration towards sustainable development. 
Aspects of integration of Global Aviation System towards sustainable development include:

\begin{tabular}{|l|l|l|l|}
\hline & $\begin{array}{l}\text { Aspects (subsystems) } \\
\text { of Global Aviation System }\end{array}$ & $\begin{array}{l}\text { Stage } \\
\text { Unification }\end{array}$ & Stage 2- Diversity \\
\hline 1 & Communication & $\begin{array}{l}\text { Global Language } \\
\text { proficiency }\end{array}$ & $\begin{array}{l}\text { Cross-cultural } \\
\text { proficiency }\end{array}$ \\
\hline 2 & $\begin{array}{l}\text { Systems architecture of } \\
\text { technological innovations }\end{array}$ & $\begin{array}{l}\text { Principle of } \\
\text { simplicity in } \\
\text { building and } \\
\text { functioning }\end{array}$ & $\begin{array}{l}\text { Complexity and } \\
\text { multifunctionality }\end{array}$ \\
\hline 3 & $\begin{array}{l}\text { General strategic } \\
\text { management }\end{array}$ & $\begin{array}{l}\text { Global Thinking } \\
\text { proficiency }\end{array}$ & $\begin{array}{l}\text { Global management } \\
\text { proficiency }\end{array}$ \\
\hline $3 \mathrm{~A}$ & $\begin{array}{l}\text { Innovations development and } \\
\text { implementation strategy }\end{array}$ & $\begin{array}{l}\text { Expectations } \\
\text { alignment, } \\
\text { sustainable } \\
\text { leadership } \\
\text { establishment, } \\
\text { research } \\
\text { community } \\
\text { building }\end{array}$ & $\begin{array}{l}\text { Particular outcomes } \\
\text { in talent nurturing, } \\
\text { technology } \\
\text { advancement, } \\
\text { Investments } \\
\text { management }\end{array}$ \\
\hline
\end{tabular}

In summary, sustainable development of global aviation system is reached with the following components: innovations;

1. Globally affluent research authorities' leadership over investments to

2. Global vision and global systems thinking development for the management of the global aviation system;

3. Global language proficiency enriched with cross-cultural communication proficiency for everyone involved with international aspects of aviation;

4. Research community development within the system, expanding and deepening worldwide technological expertise. 


\section{References}

Arnold, R., \& Wade, J. (2015). A definition of systems thinking: A systems approach. Procedia Computer Science, 44, 669 - 678.

Bjellos, D. (2012, August 13). Multicultural CRM. Retrieved from https://flightsafety.org/asw-article/multicultural-crm/

Bonser, M. (2011). How to measure and develop global thinking. Retrieved from https://sites.google.com/site/globalthinkingworld/home/how-tomeasure-global-thinking

Bonser, M. (2012). A thinking tool for global sustainability. Proceedings of the International Research Conference on December 27-28, 2011, St. Petersburg University of Management and Economy, Russia, 91-93.

Bonser, M. (2016). The nature of the world's integration and a tool for the measurement of sustainability in systems. Retrieved from https://sites.google.com/site/globalthinkingworld/home/3-the-new-eraof-the-world-s-integration

Crystal, D. (2003). English as a global language (2nd edition). Cambridge, England: University Press.

Fight Safety Foundation. (2004, March). Bracing the last line of defense. Flight Safety Digest. Alexandria, VA, USA: Author.

Gallagher, P. (2002, July 9). Jet pilots 14 seconds dilemma before fatal crash. The Scotsman, 1-2.

German Federal Bureau of Aircraft Accidents Investigations. (2004). Investigation report AX001-1-2. Retrieved from https://www.bfuweb.de/EN/Publications/Investigation\%20Report/2002/Report_02_AX 001-1-2_Ueberlingen_Report.pdf?_blob=publicationFile

Hanvey, R. (1987). An attainable global perspective. Global perspectives in education. Retrieved from https://files.eric.ed.gov/fulltext/ ED116993.pdf

Hofstede, G. (2001). Culture's consequences: Comparing values, behaviors, institutions, and organizations across nations ( $2 \mathrm{nd}$ ed). Thousand Oaks, CA: Sage.

ICAEA International conference. (2018). Building on the ICAO LPRs Communication as a human factor; New perspectives on aviation English training and testing. May 2018, ERAU, Daytona Beach, FL.

International Civil Aviation Organization. (1944). International civil aviation conference. Retrieved from https://www.icao.int/ChicagoConference/ Pages/default.aspx

Page, D., \& Trembly, A. (2015). EMS improves with crew resource management training. Journal of Emergency Medical Services, 1-3. 
Retrieved from https://www.jems.com/articles/print/volume-40/issue5/departments/back-to-basics/crew-resource-management-canimprove-crew-efficiency.year $=2015$

Pushnaya, M. (2004). The global-oriented thinking development in high school students in the conditions of the integration of curricular and extracurricular education. - SPb., APPE, Russia. 21. (Extended abstract of dissertation in Russian).

Pushnaya, M. (2018). English as an international language in the context of globalization. Intercultural Communication: Strategies and techniques of international liberal arts education. International conference proceedings, Saint Petersburg State University of Civil Aviation, Saint Petersburg, Russia. ISBN: 978-5-4334-0425-0, p.121-125. UDC 372.891 .1

Robertson, R. (1995). Glocalization: Time-space and homogeneityheterogeneity. In M. Featherstone, S. Lash, \& R. Robertson (Eds.), Global modernities, (pp. 25-44). London, UK: Sage.

US National Research Council. (2015). A review of the next generation air transportation system: Implications and importance of system architecture. Washington, DC: The National Academies Press. https://doi.org/10.17226/21721

Watkins, C., \& Walter, R. (2007). Transitioning from federated avionics architectures to integrated modular avionics. IEEE/AIAA 26th Digital Avionics Systems Conference (DASC), Dallas, Texas. doi:10.1109/DASC.2007.4391842

Whorf, B. (1956). Language, thought, and reality. In J. B Carrol (ed.) Selected writings of Benjamin Lee Whorf (pp. 246-271). Cambridge, MA: MIT Press. 